EDITORIAL NOTE

\title{
Corona Pandemic, Food Security, and Agricultural Research
}

\author{
G.A.S. Ginigaddara
}

Editor,

Sri Lankan journal of Agriculture and Ecosystems, Faculty of Agriculture, Rajarata University of Sri Lanka

Correspondence:

sanjeewanieg@agri.rjt.ac.lk

ORCID: $\underline{0000-0001-5561-1544}$
The current global health crisis has disrupted the whole world creating interrelated challenges of hunger, malnutrition, and food insecurity. Food systems all over the world are under huge stress. The supply chains have been disrupted, consumers are facing problems of accessing even basic food items and paying higher prices for some foods.

Sri Lanka took early actions to limit the COVID-19 imposing curfew from time to time for nearly over two months. The majority of people were under home hostage. Schools and universities were closed. Those who are working in various professions stopped reporting to offices physically and started working from home.

However, similar to many other countries, Sri Lanka wanted agriculture safely running as an essential business in the country to continue the food supply for markets and consumers. Though freedom was fully granted for the farmers to engage in their agricultural production activities irrespective of lockdown condition imposed in the country, farmers started to face various other problems for receiving agricultural inputs, fulfilling harvesting activities and postharvest preparations, transporting harvests to markets and even finding the right market for the products. Labour shortage mainly due to movement restrictions, social distancing rules, and illness started to impact producers, processors, traders, and others in supply chains. Farmers lost their regular markets and worried about harvesting their current crop and planting for the next season. Export bans and import restrictions created problems of reaching people the needed food items and paying unnecessarily for certain food items (e.g. turmeric powder). At the same time, loss of income and remittances limited people's purchasing ability.

People who carried out small businesses earned daily wages and served in contract basis jobs in certain firms and small-scale entrepreneurs were in more economical crisis and facing serious problems of securing their families with sustainable food supply and consumption. 
Though the government commenced the collection of food/harvests from the producers and distribution among the consumers at various locations, still some producers started complaining that they could not sell their products at right time, at the right price.

Similar to many other countries, home gardening programs boosted all over in Sri Lanka. Lots of discussions and sharing of technical information were started through social media and other mass media and, distribution programs of planting materials for home gardening got more attention from the majority in society. People who were blessed with earned adequate time due to lockdown action and work at home (saving time for roads traffics) started to use this extra time to start planting something in their home gardens. This however happened in many places without any plans. At the same time, organic farming got special attention, and efforts of starting organic farms could also be seen from small scale to large scale in various places in the country.

While all these actions started and are happening at present everywhere in the country, rescuing the nation from the food security issues and rebuilding the food supply chains to a viable level are essential steps to be taken wisely in the coming months. Rebuilding resilient local food systems and strengthening local and regional food supply chains are very much applicable for a country like Sri Lanka which is having huge biodiversity and a rich treasure of local food crops distributed across the country. At the same time, rigorous actions are needed to reinforce food collections and distribution systems and restart the cultivations in the coming season to supply nutritious food to needy people all over the country in the coming months. Special attention is needed to uplift the farming communities in agricultural areas to produce healthy and nutritious foods adequately while following sustainable farming approaches and sustained use of natural resources for agriculture. Rather than entertaining the home gardening haphazardly in the country which might not be sustainable all the time and in all localities (e.g. urban areas with very limited space and no extra water source other than drinking water supply) in the long run, strengthening the farming communities especially in major agricultural areas is a timely action to be taken as a strategy to produce healthy and nutritious foods sustainably. At the same time, these foods should be accessible to the consumers in the urban localities to a fair price and available throughout the year. For that, suitable farmers' markets and sustainable supply chains should be established. This strategy might save natural resources (e.g. reduced purified water usage for home garden plants in urban localities) enormously supporting natural resource savings in the country.

In this crisis, researchers and academic experts in agriculture have a bigger role to play. The research system which has built on mainly conducting more single or few researchers interested types of research has to be converted to transdisciplinary research to search holistic solutions for the present crisis. Researchers should move from lab to land for more applied researches searching solutions for the farmers' problems. Framing systems research 
approach has to be applied in searching strategies to strengthen local food systems focusing on farmgate to consumers. Small scale farmers need more attention and research are needed to find ways and means to make their food production systems more resilient for unexpected crises. Innovations are needed in agriculture such as precision farming techniques and timely delivery of inputs to the farmers' fields at the right quantity. "More from less" approaches are ideal in searching solutions for the problems associated with the present chemical-based agricultural approach. More revolutions with ICT based agriculture and biotechnological approaches can be used to reconceptualize food and agricultural systems for enhancing food and nutrition security of the people and reducing environmental footprints. Scientists should pay more attention to household food and nutrition security, upliftment of rural livelihoods, reconceptualizing local food systems, and local and regional food supply chains, value addition in agriculture and reduced post-harvest losses, changing peoples' food patterns entertaining consumption without wastages and strategies to empower local small scale farmers in proposing, planning and implementing research and development programs in Agriculture during this Corona pandemic. 